\title{
Extraction of vanadium compounds from the used vanadium catalyst with the potassium hydroxide solution
}

\author{
Krzysztof Mazurek*, Katarzyna Białowicz, Mieczysław Trypuć \\ Nicolaus Copernicus University, Faculty of Chemistry, Department of Chemical Technology, ul. Gagarina 7 , \\ 87-100 Toruń, Poland \\ *Corresponding author: e-mail:mazur@chem.umk.pl
}

\begin{abstract}
The paper presents the results of the research on the degree of the recovery of vanadium $(\mathrm{V})$ from the used vanadium catalyst with the use of $\mathrm{KOH}$ solution. The extraction was performed at $293-323 \mathrm{~K}$, for 0.5 to $4 \mathrm{~h}$ and the catalysts of the variable grain diameter. The concentration of the extracting solution was varied in the range $5-20 \%$. The optimal ratio of solid to liquid phase $\mathrm{S} / \mathrm{L}$ was determined. Additionally the degree of the recovery of total iron ions was presented.
\end{abstract}

Keywords: vanadium catalyst, leaching, recovery, vanadium, iron, sulfuric acid, potassium hydroxide

\section{INTRODUCTION}

For the contemporary industry, utilization of the vanadium catalyst deactivated during the industrial process, is one of the fundamental problems requiring the complex solution. The vanadium catalyst used in the technological process of $\mathrm{SO}_{2}$ oxidation to $\mathrm{SO}_{3}$ loses its activity. The waste generated in that process includes the oversize from every step of the catalyst sieving, a catalyst withdrawn from the process due to the loss of its activity, as well as the deposit of the catalyst from the industrial installations stopped due to the decreasing economical activity ${ }^{\mathbf{1 - 3}}$.

The vanadium catalyst withdrawn from the process of $\mathrm{H}_{2} \mathrm{SO}_{4}$ production is usually stored on the factory dump, therefore being a troublesome waste because of the large amount of toxic substances (eg. $\mathrm{V}_{2} \mathrm{O}_{5}, \mathrm{H}_{2} \mathrm{SO}_{4}$, alkalies), which are eluted with the precipitation into the soil. The necessity of the environment protection and high price for $\mathrm{V}_{2} \mathrm{O}_{5}$ make the utilization of the vanadium catalyst a very significant problem.

Every year $100-140$ tons of catalyst are required to fill the medium size installation of a production capacity about $300000 \mathrm{MH}$. That gives the estimate for the catalyst usage and also justifies the necessity for the research on the utilization of such large amount of vanadium waste.

There are numerous literature reports on the methods of the utilization of the used vanadium catalyst or methods for the recovery of vanadium(V) oxide ${ }^{4-10}$. Among the most frequently used are:

- addition of a certain amount of the used catalyst to the new catalytic mass

- production of ferrovanadium

- recovery of vanadium compounds from the solution by chemical methods

Chemical methods of extraction of vanadium from the used vanadium catalyst could be divided into two groups; those requiring the thermal pre-processing or not.

The former include sintering of the raw material containing vanadium with fluxing agents such as $\mathrm{NaCl}$, $\mathrm{Na}_{2} \mathrm{CO}_{3}, \mathrm{Na}_{2} \mathrm{SO}_{4}$, and subsequent elution of the sinter with different solutions (acids, bases or solutions containing vanadium(II)).

Among the chemical methods of vanadium extraction from the used vanadium catalyst mass with no prior thermal processing, the frequently reported is the extraction with $\mathrm{NaOH}$ solutions. Based on the results of the previous research ${ }^{4,7}$ the general conditions of extraction of the used catalyst with $\mathrm{NaOH}$ were determined:

- before the extraction, the catalyst should be granulated and should be granulometrically homogeneous (the grain size should not exceed $0.2 \mathrm{~mm}$ )

- the concentration of the $\mathrm{NaOH}$ solution used in the extraction should be $5 \%$

- the ratio of the solid to liquid phase should be $1: 10$

- the ratio of the solid phase to the volume of $\mathrm{H}_{2} \mathrm{O}_{2}$ used should be $1: 0.175$

- the time of extraction with the constant steering $-1 \mathrm{~h}$

The extracts obtained under these conditions contain circa $4.5 \mathrm{~g} \mathrm{~V}_{2} \mathrm{O}_{5} / \mathrm{dm}^{3}$ but also some impurities introduced together with vanadium compounds.

The method described above was an inspiration for the research on the determination of optimal conditions for vanadium $(V)$ extraction from the used vanadium catalyst with the use of $\mathrm{KOH}$ solutions.

This paper presents the results of a fragment of the research ${ }^{1,2,11-14}$ conducted at the Department of Chemical Technology UMK on the determination of the conditions for the extraction of the components of the used vanadium catalyst. The paper presents the results of the research on the degree of the recovery of vanadium $(\mathrm{V})$ with the use of $\mathrm{KOH}$ solutions of different concentration. The influence of temperature, time of extraction, $\mathrm{KOH}$ concentration and the ratio of solid to liquid phase $(\mathrm{S} / \mathrm{L})$ on the concentration of vanadium $(\mathrm{V})$ in the raffinate were also determined.

Additionally, authors have determined the concentration of iron compounds in the analyzed solutions, since these compounds are the main contaminant in the catalyst mass recovered from the sulfur-type installations. Iron causes a significant deterioration of the catalytic and physical properties of the catalyst despite its amount and form in which it was introduced. Therefore the authors decided to control the amount of the recovered iron to determine the possibility of the use the post-extraction lye to obtain new catalyst mass.

Recovery of $\mathrm{V}_{2} \mathrm{O}_{5}$ from the used vanadium catalyst with the use of chemical methods seems to be the most rational way of the utilization of that waste. Therefore most of the research on the utilization of the vanadium catalyst focus on these methods. 


\section{EXPERIMENTAL SECTION}

\section{Reagents used}

The used vanadium catalyst was obtained from the dump of the plant POLCHEM, Torun, producing the sulfuric acid with the contact method. The used vanadium catalysts are chemically and granulometrically heterogeneous materials. Their composition strongly depends on the conditions of their use, source of sulfur dioxide, as well as on the way of their storage. The catalyst samples were analyzed to determine the chemical composition with the use of the EDXRF method. The results of the analyses are presented on Table 1 and Figure 1.

Table 1. Chemical composition of the used vanadium catalysts

\begin{tabular}{|l|c|}
\hline Compound & $\begin{array}{c}\text { Content } \\
{[\%]}\end{array}$ \\
\hline $\mathrm{V}_{2} \mathrm{O}_{5}$ & 4.68 \\
\hline $\mathrm{SiO}_{2}$ & 57.31 \\
\hline $\mathrm{K}_{2} \mathrm{O}$ & 8.70 \\
\hline $\mathrm{Fe}_{2} \mathrm{O}_{3}$ & 2.59 \\
\hline
\end{tabular}

Before the research, the catalyst was granulated and devided into the required granulometric fractions with the use of the FRITSH sieve set.

$\mathrm{KOH}$ (analytical grade) POCh Gliwice.

\section{Methods}

Research on the determination of conditions of vanadium(V) and iron extraction from the used catalyst with $\mathrm{KOH}$ solution was divided into four steps:

The first step focused on the effect of the time and the concentration of the leaching solution on the rate of the process of vanadium(V) and iron recovery. The experiments were conducted at $303 \mathrm{~K}$ for the catalyst grains of $0.16-0.075 \mathrm{~mm}$ diameter. The ratio of the solid to liquid phase $\mathrm{S} / \mathrm{L}$ was kept constant at $1 / 10\left[\mathrm{~g} / \mathrm{cm}^{3}\right]$. The concentration of $\mathrm{KOH}$ solutions was $5 \%, 10 \%, 15 \%$ and $20 \%$. The extraction time was $0.5,1,2,3$ and $4 \mathrm{~h}$, respectively. The starting parameters were selected based on the results obtained for the use of $\mathrm{NaOH}$ solutions ${ }^{4,7}$.

The $5 \mathrm{~g}$ samples of the used vanadium catalyst with the grain diameter of $0.16-0.075 \mathrm{~mm}$ were put into the $100 \mathrm{ml}$ Erlenmeyer flasks with a magnetic stirrer. Next, $50 \mathrm{~cm}^{3}$ of $\mathrm{KOH}$ solution of a required concentration was added. The flasks were thermostated and intensely stirred for $0.5-4 \mathrm{~h}$. Than the solution was filtered with the sintered glass crucible. The obtained filtrate was diluted as required and subjected to the chemical analysis.

In the second step, the ratio of solid to liquid phase $(\mathrm{S} / \mathrm{L})\left[\mathrm{g} / \mathrm{cm}^{3}\right]$ was optimized and the effect of the grain diameter on the ratio of vanadium $(\mathrm{V})$ and iron recovery was determined. The extraction was performed at $303 \mathrm{~K}$ for $1 \mathrm{~h}$, using $15 \% \mathrm{KOH}$ solution. The $\mathrm{S} / \mathrm{L}$ ratio varied from $1 / 2$ to $1 / 10$ and four catalyst fractions differing by the grain diameter were investigated. The method of the experiments was the same as described for the first step.

In the third step, the effect of temperature on the ratio of vanadium $(\mathrm{V})$ and iron recovery was determined for the constant concentration of the extracting solution $(15 \%$ $\mathrm{KOH})$. The temperature ranged from 293 to $323 \mathrm{~K}$, the reaction time was 1 and $4 \mathrm{~h}$.

In the last step the extraction from the used catalyst was conducted under optimal conditions determined in the previous steps.

The yield of recovery was calculated as:

$Y_{\%}=\frac{\left[m_{M_{x} O_{y}}\right]}{\left[Z \cdot m_{\text {catalyst }}\right]} \cdot 100 \%$

where:

$\mathrm{M}=\mathrm{V}$ or $\mathrm{Fe}$,

$\mathrm{m}=$ mass $[\mathrm{g}]$

$\mathrm{Z}=$ contents of the investigated oxides in the catalyst $\left(\mathrm{V}_{2} \mathrm{O}_{5}-5 \%\right.$ and $\left.\mathrm{Fe}_{2} \mathrm{O}_{3}-1.65 \%\right)$.

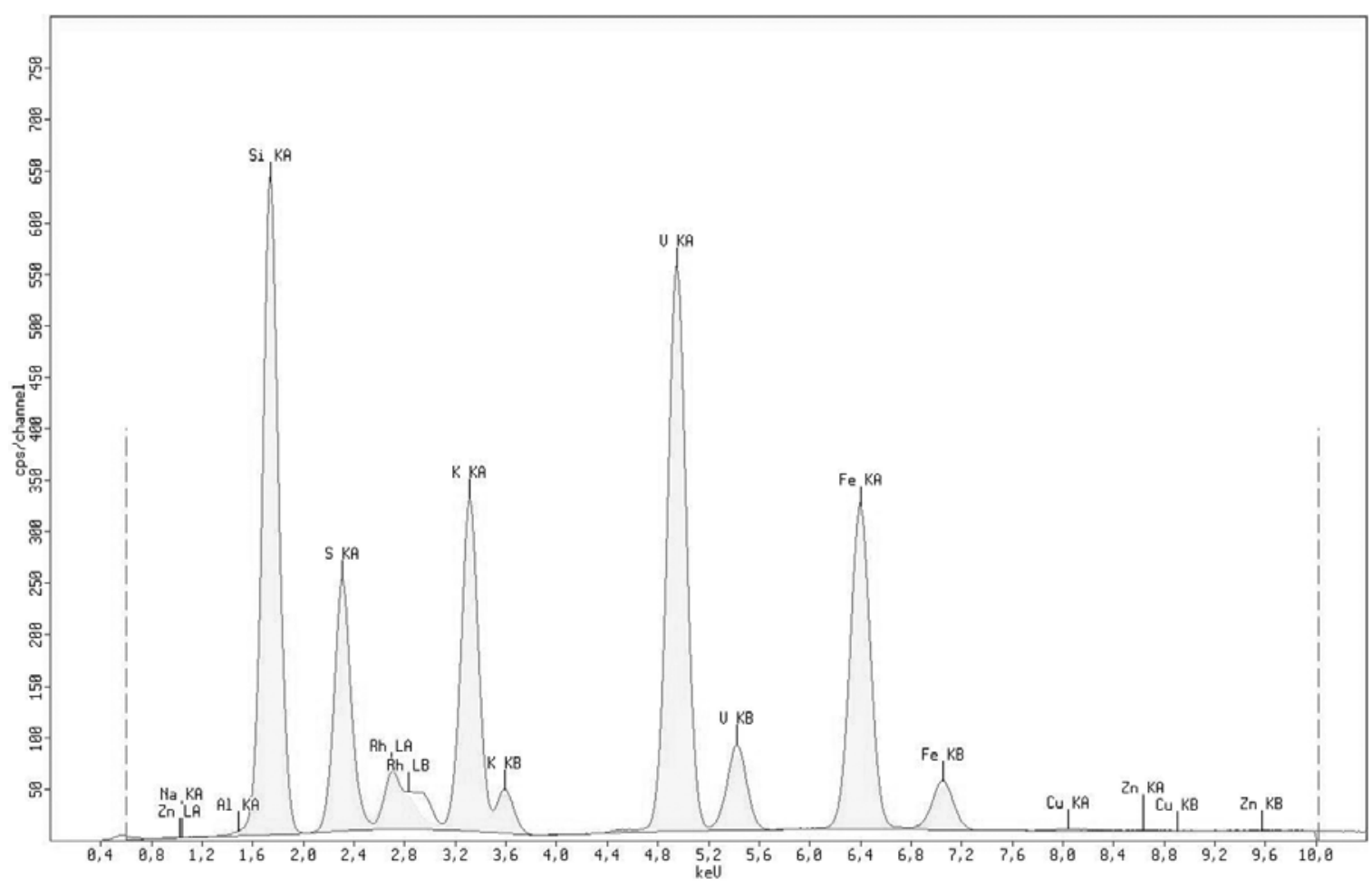

Figure 1. Quantitative composition of the spent vanadium catalyst 


\section{Analytical methods}

The concentration of vanadium(V) ions in the solutions was determined spectrophotometrically, using the peroxide method ${ }^{\mathbf{1 5}}$. This method is based on the ability of vanadium $(\mathrm{V})$ to form in the presence of sulfuric acid and hydrogen peroxide, the compounds $\mathrm{VO}_{2} \mathrm{X}$ or $\mathrm{VO}_{2} \mathrm{X}_{5}$ where $\mathrm{X}$ is a monoanion. Vanadium(V) and hydrogen peroxide react in the equimolar amounts according to the following equation:

$(\mathrm{VO})_{2}\left(\mathrm{SO}_{4}\right)_{3}+2 \mathrm{H}_{2} \mathrm{O}_{2} \rightarrow\left(\mathrm{VO}_{2}\right)_{2}\left(\mathrm{SO}_{4}\right)_{3}+2 \mathrm{H}_{2} \mathrm{O}$

forming the stable red-brown complex. That compound, revealing a maximum absorbance at wavelength $450 \mathrm{~nm}$ and the molar absorption coefficient is $300 \mathrm{dm}^{3} \cdot \mathrm{mol}^{-1} \cdot \mathrm{cm}^{-1}$, is suitable for the spectrophotometric determination of the vanadium amounts.

The analyses were performed with the double-beam $\mathrm{U}-2000 \mathrm{UV} / \mathrm{Vis}$ spectrophotometer (HITACHI).

The total concentration of iron in solutions was determined using the EDXRF method ${ }^{\mathbf{1 6}}$. The analyses were performed with the MiniPal4 PANalytical compact energy dispersive X-ray spectrometer.

\section{RESULTS AND DISCUSSION}

Table 2, figures 2 and 3 presents the results of chemical analyses obtained in the first step and used to determine the effect of the concentration of $\mathrm{KOH}$ solutions and the time of contact between the solid and liquid phases on the degree of vanadium( $(\mathrm{V})$ and iron recovery. The concentration of vanadium $(\mathrm{V})$ in the raffinate increases with the increasing time of extraction for the constant $\mathrm{KOH}$ concentration. However, that increase is not larger than $4 \%$. The degree of vanadium(V) recovery increases with the increasing concentration of the extracting solution. The smallest increase of vanadium( $\mathrm{V}$ ) concentration in the raffinate was found with the $\mathrm{KOH}$ concentration change

Table 2. The effect of $\mathrm{KOH}$ concentration and the extraction time on the degree of vanadium $(\mathrm{V})$ recovery from the used vanadium catalyst $(\mathrm{T}=303 \mathrm{~K}, \mathrm{~S} / \mathrm{L}=$ $1 / 10 ; \phi: 0.16-0.075 \mathrm{~mm})$

\begin{tabular}{|c|c|c|}
\hline $\begin{array}{c}\mathrm{KOH} \\
\text { concentration } \\
{[\%]}\end{array}$ & $\begin{array}{l}\text { Time } \\
\text { [h] }\end{array}$ & $\begin{array}{l}\text { Degree of vanadium(V) recovery } \\
{[\%]}\end{array}$ \\
\hline \multirow{5}{*}{5} & 0.5 & 68.08 \\
\hline & 1 & 68.92 \\
\hline & 2 & 69.75 \\
\hline & 3 & 70.60 \\
\hline & 4 & 71.44 \\
\hline \multirow{5}{*}{10} & 0.5 & 71.43 \\
\hline & 1 & 72.25 \\
\hline & 2 & 73.11 \\
\hline & 3 & 73.96 \\
\hline & 4 & 74.79 \\
\hline \multirow{5}{*}{15} & 0.5 & 73.97 \\
\hline & 1 & 74.80 \\
\hline & 2 & 75.63 \\
\hline & 3 & 76.45 \\
\hline & 4 & 77.32 \\
\hline \multirow{5}{*}{20} & 0.5 & 74.25 \\
\hline & 1 & 75.43 \\
\hline & 2 & 76.47 \\
\hline & 3 & 77.12 \\
\hline & 4 & 78.16 \\
\hline
\end{tabular}

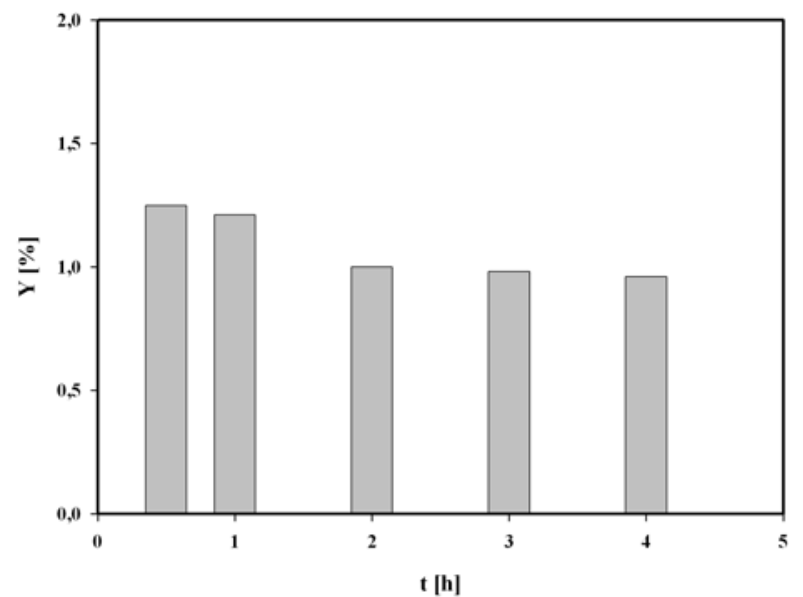

Figure 2. Dependency on the efficiencies of the iron compounds leaching process on the time of the catalyst leaching $\left(\mathrm{c}_{\mathrm{KOH}}=15 \% ; \mathrm{T}=303 \mathrm{~K} ; \mathrm{S} / \mathrm{L}=1 /\right.$ $10 ; \phi: 0.16-0.075 \mathrm{~mm})$

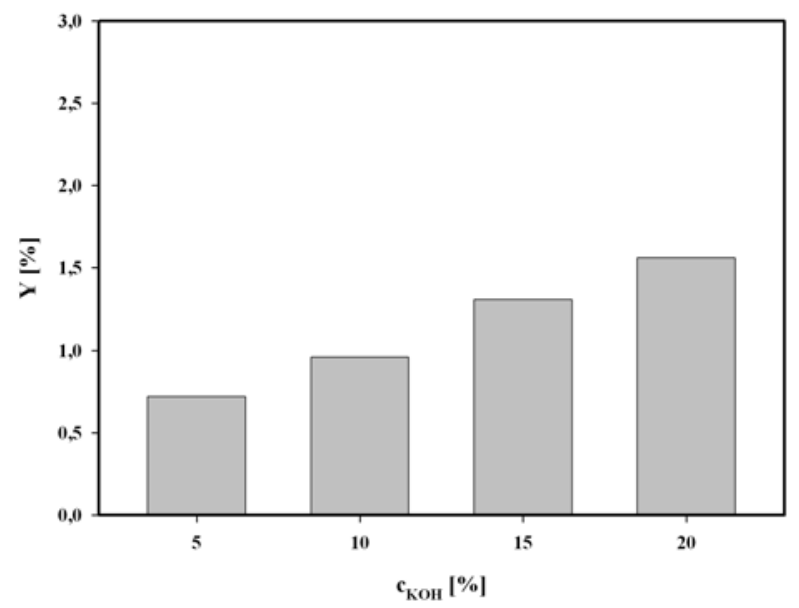

Figure 3. Dependency of the yield of iron compounds recovery on the potassium hydroxide concentrations in the leaching solution $(\mathrm{T}=303 \mathrm{~K} ; \mathrm{S} / \mathrm{L}=1 / 10$; $\phi: 0.16-0.075 \mathrm{~mm}$ )

from $15 \%$ to $20 \%$. Therefore, the subsequent investigations were performed with the use of $15 \% \mathrm{KOH}$ solution.

Data presented in Figure 2 indicate that the yield of the recovery of iron compounds decreases in time at the temperature $303 \mathrm{~K}$ and reaches the minimum past 4 hour leaching process.

The reported data in Figure 3 indicates that the potassium hydroxide concentration has the smallest effect on the yield of the recovery of iron compounds. In that case the increase of the $\mathrm{KOH}$ concentration from 5 to $20 \%$ by mass results in the yield increase by approximately $0.8 \%$.

The raffinate density varies from 1.063 to $1.173 \mathrm{~g} / \mathrm{cm}^{3}$.

Table 3 presents the results of the second step focusing on the effect of catalyst granulation and changes of the ratio of solid to liquid phase $(\mathrm{S} / \mathrm{L})$ on the amount of eluted vanadium(V).

The data analysis reveals that the degree of vanadium(V) recovery increases with the increasing granulation for the constant $\mathrm{S} / \mathrm{L}$ ratio. Also for every catalyst fraction, the $\operatorname{vanadium}(\mathrm{V})$ concentration in the raffinate increases with the $\mathrm{S} / \mathrm{L}$ changing from $1 / 2$ to $1 / 10$. The best results in this step were obtained for the catalyst fraction with the small- 
Table 3. The effect of the $\mathrm{S} / \mathrm{L}$ ratio and the catalyst grain diameter on the degree of vanadium(V) recovery $\left(\mathrm{T}=303 \mathrm{~K}, \mathrm{c}_{\mathrm{KOH}}=15 \%, \mathrm{t}=1 \mathrm{~h}\right)$

\begin{tabular}{|c|c|c|}
\hline $\begin{array}{l}\text { Catalyst grain } \\
\text { diameter } \\
{[\mathrm{mm}]}\end{array}$ & $\begin{array}{c}\mathrm{S} / \mathrm{L} \\
{\left[\mathrm{g} / \mathrm{cm}^{3}\right]}\end{array}$ & $\begin{array}{c}\text { Degree of vanadium(V) } \\
\text { recovery } \\
{[\%]}\end{array}$ \\
\hline \multirow{5}{*}{$0.75-0.385$} & $1 / 2$ & 67.76 \\
\hline & $1 / 4$ & 68.54 \\
\hline & $1 / 6$ & 69.29 \\
\hline & $1 / 8$ & 71.03 \\
\hline & $1 / 10$ & 71.77 \\
\hline \multirow{5}{*}{$0.385-0.16$} & $1 / 2$ & 69.15 \\
\hline & $1 / 4$ & 70.26 \\
\hline & $1 / 6$ & 71.57 \\
\hline & $1 / 8$ & 72.40 \\
\hline & $1 / 10$ & 73.68 \\
\hline \multirow{5}{*}{$0.16-0.075$} & $1 / 2$ & 70.05 \\
\hline & $1 / 4$ & 72.24 \\
\hline & $1 / 6$ & 73.04 \\
\hline & $1 / 8$ & 73.43 \\
\hline & $1 / 10$ & 74.80 \\
\hline \multirow{5}{*}{$<0.075$} & $1 / 2$ & 72.10 \\
\hline & $1 / 4$ & 74.05 \\
\hline & $1 / 6$ & 75.11 \\
\hline & $1 / 8$ & 76.00 \\
\hline & $1 / 10$ & 77.88 \\
\hline
\end{tabular}

est grain diameter ( $\phi$ below $0.075 \mathrm{~mm}$ ) and the solid to liquid phase ratio $\mathrm{S} / \mathrm{L}=1 / 10$. The yield obtained for these conditions was $77.88 \%$ of vanadium(V) contents in the catalyst.

In the next step the effect of temperature was determined. The extraction was performed with $15 \%$ solution of $\mathrm{KOH}$ for 1 and $4 \mathrm{~h}$ and ratio $\mathrm{S} / \mathrm{L}=1 / 10$, for the catalyst fraction of $\phi$ below $0.075 \mathrm{~mm}$. The results are presented in Table 4 and in Figure 4 . The data reveal the increase of the degree of vanadium $(V)$ recovery with the increasing temperature for the selected time of extraction. For both the $1 \mathrm{~h}$ and $4 \mathrm{~h}$ period of extraction that increase was $7 \%$ with the temperature changed from 293 to $323 \mathrm{~K}$. Also, the longer time of extraction results in the increase of the vanadium $(\mathrm{V})$ concentration in raffinate. The highest concentration was obtained at $323 \mathrm{~K}$ for $4 \mathrm{~h}$ extraction time. The range of raffinate density was $1.126-1.141$ $\mathrm{g} / \mathrm{cm}^{3}$, and the density increased with the increasing temperature and the time of elution.

Data presented in Figure 4 indicate that the yield of recovery of iron compounds decreases systematically with the increasing temperature from 293 to 313 K. Further

Table 4. The effect of temperature on the degree of vanadium $(\mathrm{V})$ recovery from the used vanadium catalyst $\left(\mathrm{c}_{\mathrm{KOH}}=15 \%, \mathrm{~S} / \mathrm{L}=1 / 10 ; \phi\right.$ : below $\left.0.075 \mathrm{~mm}\right)$

\begin{tabular}{|c|c|c|}
\hline $\begin{array}{c}\text { Temperature } \\
{[\mathrm{K}]}\end{array}$ & $\begin{array}{c}\text { Time } \\
{[\mathrm{h}]}\end{array}$ & $\begin{array}{c}\text { Degree of vanadium(V) recovery } \\
{[\%]}\end{array}$ \\
\hline \multirow{2}{*}{293} & 1 & 75.92 \\
\cline { 2 - 3 } & 4 & 78.15 \\
\hline \multirow{2}{*}{303} & 1 & 77.88 \\
\cline { 2 - 3 } & 4 & 80.37 \\
\hline \multirow{2}{*}{313} & 1 & 81.70 \\
\cline { 2 - 3 } & 4 & 85.42 \\
\hline \multirow{2}{*}{323} & 1 & 83.12 \\
\cline { 2 - 3 } & 4 & 86.29 \\
\hline
\end{tabular}

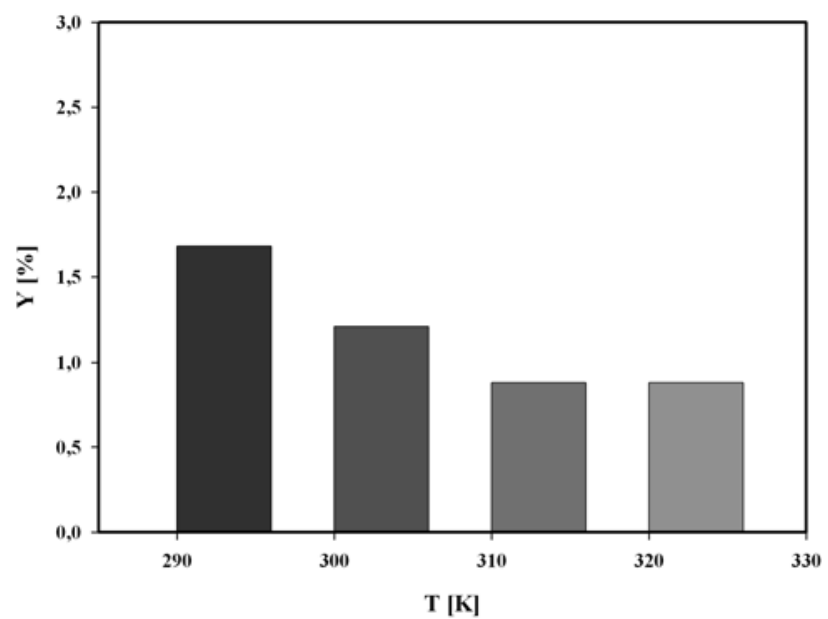

Figure 4. Dependency on the efficiencies of the iron compounds leaching process on the temperature of the catalyst leaching $\left(\mathrm{c}_{\mathrm{KOH}}=15 \% ; \mathrm{S} / \mathrm{L}=1 / 10\right.$; $\phi$ : below $0.075 \mathrm{~mm}$ )

raising of the temperature does not lead to a significant decrease of that concentration.

The research was concluded with the extraction of vanadium(V) from the used catalyst under the following conditions: $15 \% \mathrm{KOH}, \mathrm{T}=323 \mathrm{~K}, \mathrm{t}=4 \mathrm{~h}, \mathrm{~S} / \mathrm{L}=1 / 10$, the catalyst grains $\phi$ : below $0.075 \mathrm{~mm}$. The achieved degree of the recovery of vanadium(V) from the catalyst was $86 \%$. Apart from vanadium and potassium compounds a small amount of iron compounds, whose concentration is $10-20 \mathrm{ppm}$, goes to the solution

The selected catalyst samples after the extraction with the use of $\mathrm{KOH}$ solutions were analyzed to determine the chemical composition with the use of the EDXRF method. The results of the analyses are presented in Table 5 and Figure 5. The large increase in the content of potassium compounds in the catalyst sample after the extraction compared to the catalyst before the extraction is related to the $\mathrm{K}_{2} \mathrm{SO}_{4}$ precipitation. The qualitative composition of the solution sample after the extraction is presented in Figure 6.

Figure 7 presents the comparison of the results of the temperature influence of the leaching process on vanadium compounds recovery using potassium hydroxide and sodium hydroxide solutions for the optimal conditions $(\mathrm{t}$ $=4 \mathrm{~h}, \mathrm{c}=15 \%, \mathrm{~S} / \mathrm{L}=1 / 10, \phi$ : below 0.075$)$. The degree of vanadium(V) recovery is similar for both leaching solutions ${ }^{\mathbf{1 7}}$. However, the method of the spent vanadium catalyst utilization with $\mathrm{NaOH}$ requires an additional step separation of vanadium compounds from the solution ${ }^{4-7}$. The direct precipitation yielded low recovery of vanadium and the high contents of this metal in the residual solution. It is necessary to apply the organic solvent extraction. But it greatly increases the costs of the process. The use of $\mathrm{KOH}$ solution doesn't require separation of

Table 5. Chemical composition of the used vanadium catalyst sample after the extraction

\begin{tabular}{|l|c|}
\hline Compound & $\begin{array}{c}\text { Content } \\
{[\%]}\end{array}$ \\
\hline $\mathrm{V}_{2} \mathrm{O}_{5}$ & 0.72 \\
\hline $\mathrm{SiO}_{2}$ & 57.5 \\
\hline $\mathrm{K}_{2} \mathrm{O}$ & 21.7 \\
\hline $\mathrm{Fe}_{2} \mathrm{O}_{3}$ & 3.50 \\
\hline
\end{tabular}




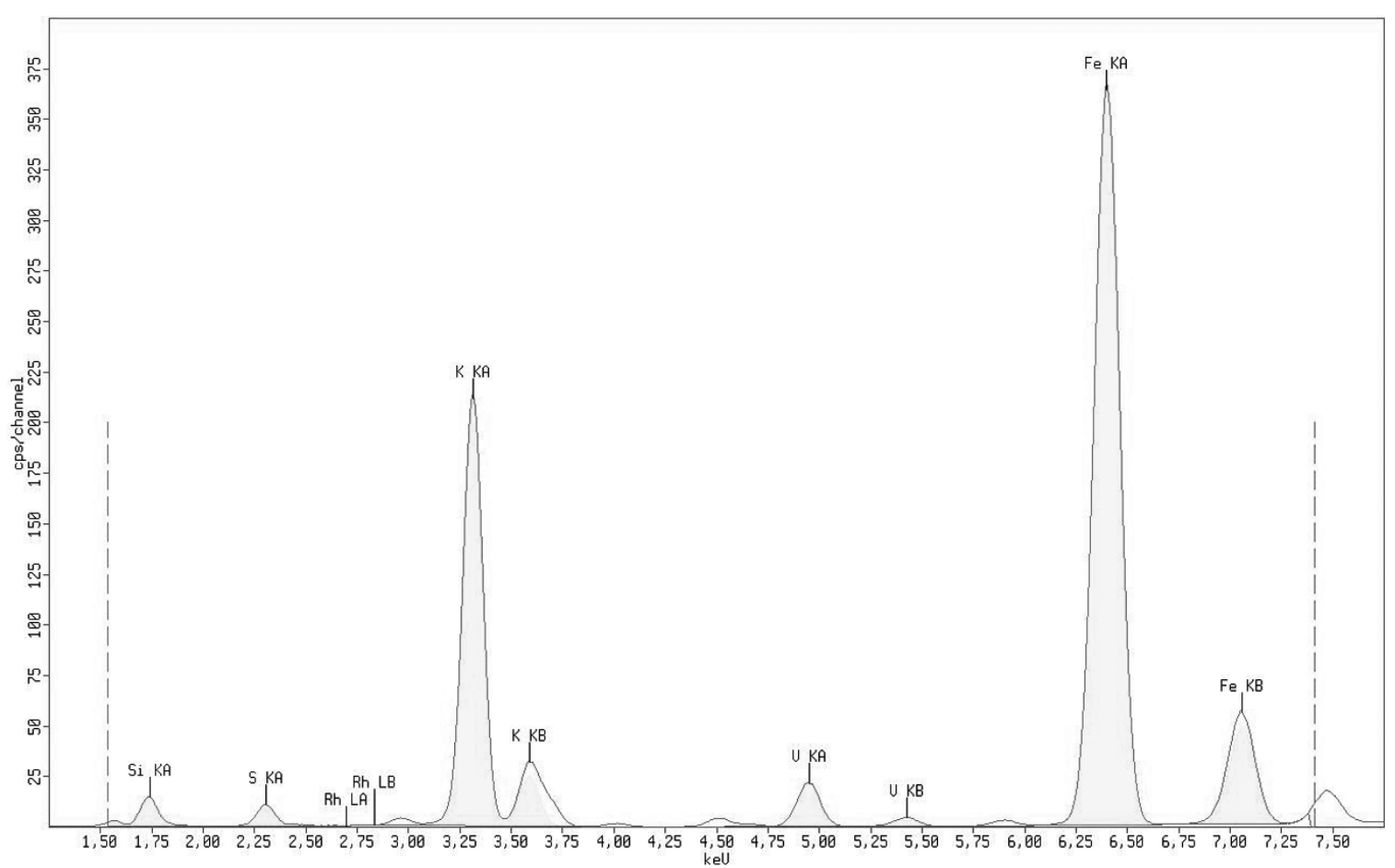

Figure 5. Quantitative composition of the spent vanadium catalyst after the extraction

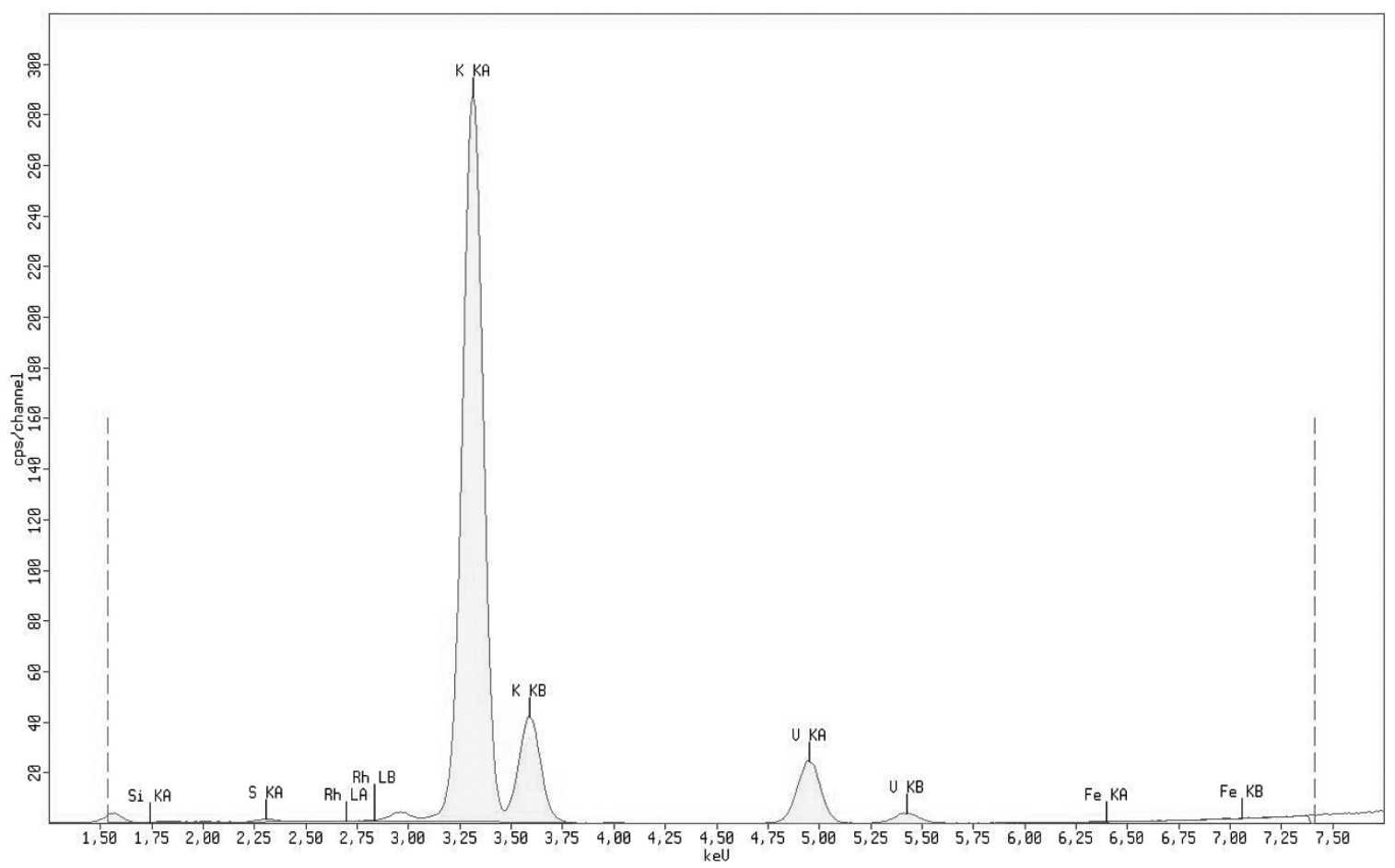

Figure 6. Quantitative composition of the solution after the extraction

vanadium from the solution. The solution, after the correction of its composition, can be directly used for the production of the new mass of vanadium catalyst.

Figure 8 presents the conceptual process flow sheet for the recovery of vanadium from the spent catalyst with potassium hydroxide solutions and the production of the new catalyst.

The new catalyst will be produced using the wet technique based on the recovered compounds:

- natural or recovered $\mathrm{SiO}_{2}\left(\min .85 \% \mathrm{SiO}_{2} ; \max 0.5 \%\right.$ $\left.\mathrm{Fe}_{2} \mathrm{O}_{3}\right)$, roasted $(\mathrm{T}=673 \mathrm{~K})$,

- technical $\mathrm{V}_{2} \mathrm{O}_{5}$ (grain size: below $0.075 \mathrm{~mm}$ ) and $\mathrm{KOH}$, for the correction of the solution composition,
$-\mathrm{K}_{2} \mathrm{CO}_{3}$,

- ground sulfur,

- sulfuric(VI) acid,

- texture modifier.

A possible production process will proceed according to the flow sheet presented in the manuscript ${ }^{18}$.

\section{Summary}

1. The degree of vanadium(V) recovery from the used vanadium catalyst increases with the increasing concentration of the extracting solution. The optimal concentration of $\mathrm{KOH}$ solution is $15 \%$, and higher concentrations cause only an insignificant increase of the degree of recovery. 


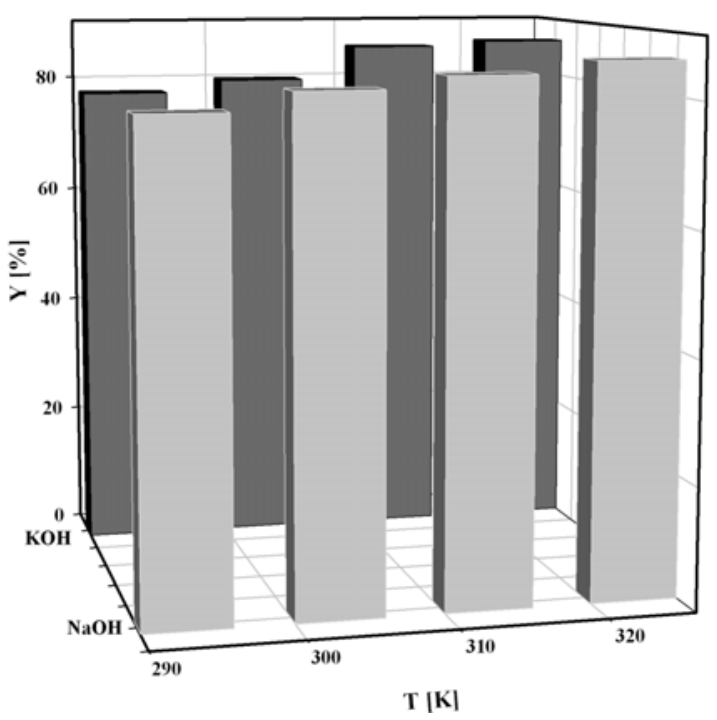

Figure 7. The comparison of the results of vanadium compounds recovery using potassium hydroxide and sodium hydroxide solutions

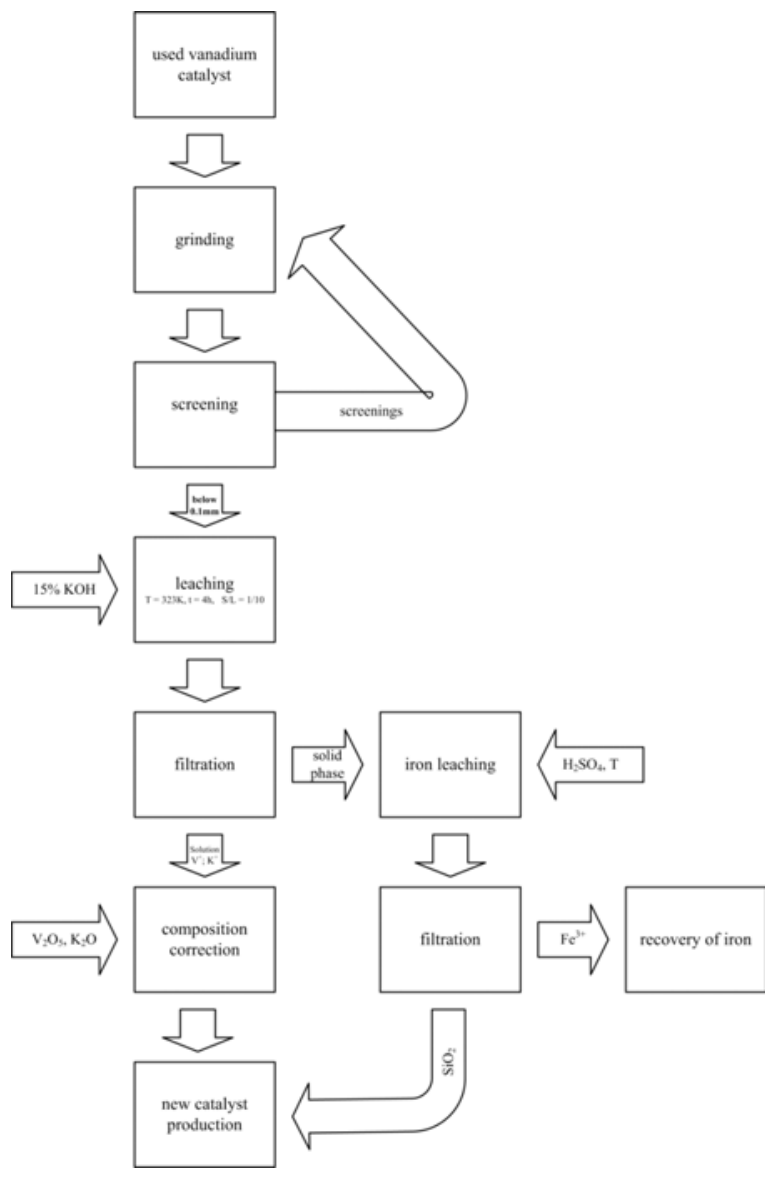

Figure 8. A conceptual process flow sheet for the recovery of vanadium from a spent catalyst with potassium hydroxide solutions and the new catalyst production

2. Extension of the time of the contact between the solid and liquid phases results in the increase of the extraction yield.

3. The degree of vanadium $(\mathrm{V})$ recovery increases with the increasing temperature.

4. Concentration of vanadium $(\mathrm{V})$ in raffinate increases with the decreasing size of the catalyst grains.

5. Maximum degree of vanadium $(\mathrm{V})$ recovery from the used vanadium catalyst $(86 \%)$ was achieved for the extraction conditions: $15 \% \mathrm{KOH}, \mathrm{T}=323 \mathrm{~K}, \mathrm{t}=4 \mathrm{~h}, \mathrm{~S} / \mathrm{L}$ $=1 / 10, \phi:$ below $0.075 \mathrm{~mm}$.
6. Low leakage of iron compounds from the catalyst into the solution was observed.

\section{Acknowledgement}

This work was supported by science resources of the Polish Ministry of Science and Higher Education (2007 - 2009) under Research and Development Project No. R05 03502.

\section{LITERATURE CITED}

1. Trypuć, M., Grzesiak, P., Mazurek, K. \& Grobela, M. (2007). The comprehensive management of the hazardous vanadium catalysts waste used for the oxidation of $\mathrm{SO}_{2}$. Poznan, Poland: WN IOR (in Polish).

2. Grzesiak, P. (2006). Utilization of industrial waste from sulfuric acid production processes. Przem. Chem. 8 - 9, 1015 - 1019 (in Polish).

3. Grzesiak, P. (2005). Vanadium catalysts for the oxidation of $\mathrm{SO}_{2}$. Poznań, Poland: WN IOR (in Polish).

4. Anioł, S., Korolewicz, T. \& Kubala, J. (1997). Investigations concerning the recovery of $\mathrm{V}_{2} \mathrm{O}_{5}$ from the spent vanadium catalyst for the production of sulphuric acid. Polish $J$. Appl. Chem. 41(1-2), 25 - 34.

5. Anioł, S., Korolewicz, T. \& Kubala, J. (1997). Attempts to recovery $\mathrm{V}_{2} \mathrm{O}_{5}$ from spent vanadium catalysts. Polish $J$. Appl. Chem. 41(3), 193 - 202.

6. Anioł, S., Korolewicz, T. \& Kubala, J. (1995). Investigations on $\mathrm{V}_{2} \mathrm{O}_{5}$ recovery from spent vanadium catalysts. Polish J. Appl. Chem. 39(1), $111-114$.

7. Anioł, S., Korolewicz, T. \& Kubala, J. (2002). Polish Patent No. 183269. Warsaw: Polish Patent Office.

8. Lasiewicz, K., Wesołowski, J., Pawlęty, R. \& Zawadzki, B. (1973). Polish Patent No. 67 525. Warsaw: Polish Patent Office.

9. Zawadzki, B., Wilk, E., Kończal, J., Tomczak, J. \& Bajkowski, C. (1987). Polish Patent No. 135 966. Warsaw: Polish Patent Office.

10. Khorfan, S., Wahoud, A. \& Reda, Y. (2001). Recovery of vanadium pentaoxide from spent catalyst used in the manufacture of sulphuric acid. Periodica Polytechnica Ser. Chem. Eng. 45(2), 131 - 137.

11. Grzesiak, P., Motała, R., Grobela, M., Trypuć, M. \& Mazurek, K. (2007). The influence of the conditions and worktime on the waste vanadic catalyst amount. Pol. J. Chem. Technol. 9(3), 73 - 76. DOI: 10.2478/v10026-007-0058-z.

12. Trypuć, M., Mazurek, K., Kiełkowska, U. \& Drużyński, S. (2007). Utilization of used contact masses from the oxidation state of sulfur(IV) oxide to sulfur(VI) oxide. Pol. J. Chem. Technol. 9(3), 26 - 28. DOI: 10.2478/v10026-007-0047-2.

13. Mazurek, K., Trypuć, M., Białowicz, K. \& Drużyński, S. (2008). The influence of leaching solution $\mathrm{pH}$ and addition of peroxide hydrogen on the recovery of some components from the used vanadium catalyst with urea solutions. Pol. J. Chem. Technol. 10(4), 34 - 36. DOI: 10.2478/v10026-008-0044-0.

14. Mazurek, K. (2009). Research on the development of optimal parameters of potassium compounds leaching from spent catalysts used for oxidation of sulfur(IV) oxide. Przem. Chem. 9, 1033 - 1036 (in Polish).

15. Szczepaniak, W. (2004). Instrumental methods in analytical chemistry. Warsaw, Poland: PWN (in Polish).

16. Brouwer, P. (2006). Theory of XRF. Almelo, Netherlands: Panalytical.

17. Kiełkowska, U., Białowicz, K., Trypuć, M., Mazurek, K. \& Grzesiak, P. (2008). Sulfuric acid - new opportunities, Extraction of vanadium compounds from the spent vanadium catalyst using NaOH solution (pp. 311 - 317). Poznań, Poland: WN IOR (in Polish).

18. Grzesiak, P., Mazurek, K., Trypuć, M., Grobela, M., Motała, R. \& Białowicz, K. (2010). The comprehensive management of the hazardous vanadium catalysts waste used for the oxidation of $\mathrm{SO}_{2}$. Part II: Production of new catalyst. Przem. Chem. (in press) (in Polish). 